University of Massachusetts Amherst ScholarWorks@UMass Amherst

Resource Economics Department Faculty

Publication Series

Resource Economics

2000

\title{
A test of nutritional quality signaling in food markets prior to implementation of mandatory labeling
}

EM Mojduszka

JA Caswell

Follow this and additional works at: https://scholarworks.umass.edu/resec_faculty_pubs

\section{Recommended Citation}

Mojduszka, EM and Caswell, JA, "A test of nutritional quality signaling in food markets prior to implementation of mandatory labeling" (2000). American Journal of Agricultural Economics. 42.

Retrieved from https://scholarworks.umass.edu/resec_faculty_pubs/42 


\title{
A Test of Nutritional Quality Signaling in Food Markets Prior to IMPLEMENTATION OF MANDATORY LABELING
}

\author{
Eliza M. Mojduszka and Julie A. Caswell
}

\begin{abstract}
In May 1994, new nutrition labeling regulations went into effect in the United States requiring mandatory disclosure of information on the nutritional content of foods. This article uses Grossman's model of totally effective quality signaling to evaluate whether markets were effective in information provision prior to the new regulation. If markets were effective in providing information to consumers on the nutritional quality of foods the new regulation would be unnecessary. The results of the logistic model, where the probability of voluntary information disclosure is linked to the nutritional quality of food products and their prices, indicate that private quality signaling was not reliably at work in food markets prior to implementation of the mandatory nutrition labeling regulation.
\end{abstract}

Key words: food markets, nutrition labeling, quality signaling.

The promulgation of the Nutrition Labeling and Education Act (NLEA) in 1990 marked a major step toward stricter nutrition labeling regulation in the United States. The NLEA went into effect in May 1994, requiring mandatory nutrition labeling in the form of a standardized nutrition information panel that shows the amounts of the macro- and micronutrients found in a food. In addition, voluntary nutrient content and health claims that are made outside the standardized information panel are circumscribed by the law. Prior to implementation of the NLEA, nutrition labeling was provided by manufacturers on a voluntary basis and government requirements concerning nutrient content and health claims made on food packages were much less stringent.

The NLEA relies heavily on requirements for information disclosure in an attempt to encourage consumers to demand foods with better nutritional profiles and to inspire manufacturers to produce higher quality foods. Information regulation might be very valuable in the case of nutrition because consumers often cannot accurately evaluate the nutritional quality of specific brands of food products. Following Nelson $(1970,1974)$ and

Eliza M. Mojduszka is a senior post-doctoral research associate and Julie A. Caswell is a professor, Department of Resource Economics, University of Massachusetts at Amherst.

This research was supported by the Food Marketing Policy Center, University of Connecticut and by subcontract at the University of Massachusetts.
Darby and Karni, we can distinguish three groups of product attributes that explain how consumers learn about the quality of the products they purchase: search attributes (consumers can determine product quality at the point of purchase by looking at the product, examining, or researching it), experience attributes (consumers cannot determine product quality until they buy the good and use it), and credence attributes (the quality cannot be learned even after consumption). As Caswell and Mojduszka (1996) argue, the nutritional attributes of specific brands of food should in general be viewed as credence attributes. Therefore, if manufacturers are required to provide reliable information to consumers, nutritional quality can become a search attribute consumers can evaluate at the point of purchase.

High-quality products may not be supplied in markets with imperfect and asymmetric information. If consumers have limited information about product quality, the markets may not exist or if they exist, the quality produced may be lower than in a world of perfect information. Market performance in the provision of high-quality goods depends greatly on the effectiveness of quality signaling by sellers to buyers.

Quality signaling models provide valuable insights into how information on the quality of experience attributes can be transmitted from producers to consumers, and as a 
result help us understand how markets for quality work. For example, in his "market for lemons" model Akerlof considers a case where sellers cannot signal quality effectively so that the market may disappear completely or only the lowest quality products may be sold. On the other hand, Grossman's signaling model provides quite different results due to assumptions of totally effective, truthful, and costless quality signaling and verification of claims. Here markets for varying levels of quality exist and operate smoothly.

Akerlof's model of totally ineffective quality signaling is not applicable to nutrition labeling because a level of voluntary and truthful labeling occurred prior to the NLEA. Grossman's model provides an attractive framework for testing the effectiveness of the voluntary quality signaling process for nutrition because its final outcome depicts full transmission of information to consumers and a well functioning market for quality. Markets may supply reasonably adequate information to consumers on product quality. If markets were effective in provision of information, establishing new regulations for mandatory nutrition labeling would have little effect on the demand and supply of food. The new regulations would, in fact, be unnecessary. The impact of the NLEA depends on how the information environment changed after its implementation.

As a means to begin to assess the impact of the NLEA, we use Grossman's totally effective quality signaling thesis to test the overall effectiveness of markets in providing information on the nutritional quality of food products in the period from 1992 to 1993 , when labeling was voluntary. After 1994 , quality signaling was totally effective in the sense that nutrition labels were mandatory and available on virtually all packaged food products sold in the United States. First, we outline the totally effective quality signaling hypothesis. Second, we specify and estimate an empirical model where the probability of a voluntary information disclosure is linked to the nutritional quality of food products and their prices. The final section provides a summary of results and conclusions.

\section{The Totally Effective Quality Signaling Hypothesis}

Many quality attributes of market goods are not known to consumers and in some cases may not be known to producers. Models developed by Akerlof, Grossman, and other researchers explore the conditions under which information on product quality could be effectively supplied by markets and which allow for products of varying quality to be sold. Specifically, in his model Grossman assumes that manufacturers can make ex-post verifiable claims, that verification of these claims is costless, that manufacturers never lie, and that consumers know that manufacturers will make the most favorable claim possible for their products. Manufacturers who can make a quality claim (e.g., effectively use a nutrition information panel on their product) will do so and consumers will assume that any firm not making a claim has low-quality products. Thus, consumers can learn about a product's attributes before purchase by examining the product's claims or lack of them. In the period 1992-93 when nutrition labeling was voluntary, Grossman's model would have been effectively at work if high nutritional profile products carried nutrition information panels and those with low nutritional quality did not. Thus, the absence of nutrition labeling might be a good indicator of the low nutritive value of products.

Here product quality is defined, using Lancaster's approach, as a bundle of characteristics (attributes) that determine the performance of a given product (Lancaster). Similarly, the term quality of a food product is used to refer to overall characteristics (attributes) possessed by a product, for example, food safety, nutritional, value, package, and process attributes (Hooker and Caswell). The nutritional quality of a food product is viewed as an objective measure and is expressed by the amounts of different nutrients contained by the product. Large amounts of desirable nutrients (e.g., fiber, protein, vitamins) in a product indicate its high nutritional quality while large amounts of undesirable nutrients (e.g., fat, cholesterol, sodium) indicate its low nutritive value.

If the market's operation results in full quality disclosure to consumers, government regulation of nutrition labeling would be unnecessary. As Ippolito and Mathios (1990, 1993) suggested, this process would place the fewest constraints on manufacturers while still providing full and accurate information to consumers. In addition, Caswell noted that if this process was at work, we would expect to find nutrition labeling on products with 
good nutrition profiles and absent on those with less desirable profiles. A previous study of national brand meat and poultry products conducted in 1991 by Public Voice for Food and Health Policy could be interpreted to show such a pattern (Ingersoll). Therefore the hypothesis tested is that voluntary labeling of the nutritional content of food products in the United States conformed to Grossman's quality signaling thesis prior to implementation of the NLEA and that this resulted in an information pattern in which products with higher nutritional quality were labeled and those with lower quality were not.

\section{Empirical Specification of the Logit Model}

To test the hypothesis we constructed an empirical model where the presence of a nutrition information panel on a food product is assumed to be a function of certain economic and product profile variables. This relationship can be represented by a statistical model:

$$
\begin{gathered}
Y_{i}=\alpha_{i}+\sum_{j=1}^{k} \beta_{j} X_{i j}+\beta_{k+1} P_{i}+e_{i}, \\
i=1, \ldots, N
\end{gathered}
$$

where $Y_{i}$ represents the presence of a nutrition information panel (food label) on the $i$ th food product, $X_{i j}$ is the amount of nutrient $j$ in product $i, P_{i}$ is the price of the $i$ th product, $\alpha_{i}$ is the intercept, $\beta_{j}$ and $\beta_{k+1}$ are the coefficients to be estimated, and $e_{i}$ is a stochastic error term. The dependent variable, $Y_{i}$, is a discrete (binary) manufacturer's choice variable and is defined as $Y_{i}=1$ if a nutrient content panel is present on the ith product, and $Y_{i}=0$ if not. Due to difficulties in the use of standard linear regression techniques for the discrete choice model, several alternative procedures such as probit and logit models were described by Maddala. The logit model is used in this study.

The explanatory variables are economic variables such as prices of food products, as well as nutrition profile variables such as calories, fat, cholesterol, sodium, fiber, and other macro- and micronutrient variables. If the data supported totally effective quality signaling, the estimated coefficients of undesirable nutrients such as fat, cholesterol, and sodium-nutrients that most consumers worry about having too much of rather than too little-would be negative, showing that the higher their levels in a food the lower the probability of the nutrition information panel being present. Manufacturers of low nutritional quality brands would not want to disclose this information to consumers. On the other hand, the estimated coefficients of desirable nutrients such as fiber, protein, and vitamins would be positive because it would be in the manufacturers' interest, in order to maximize profits, to disclose information about the high nutritional quality of their brands.

Nutrient content variables are used to measure the nutritional quality of foods in this test of the Grossman thesis. An alternative approach is to construct and compute composite indexes of nutritional quality for each food product examined and use them as the independent variable. Utilizing this estimation technique might provide further insights. However, few indexes of overall nutritional quality exist. In addition, this approach would assume that consumers compute an overall nutritional quality index for food products rather than looking at nutrients separately.

Price represents the only economic variable that was included in the logit model. This variable was used as a proxy for manufacturers' production costs (marginal cost). Economic theory suggests that it is more costly to produce higher quality products and therefore consumers have to pay higher prices for them. In addition, Frazao and Allshouse found that nutritionally improved versions of foods had higher prices than regular versions. Thus, if higher quality products were labeled (Grossman), the estimated coefficient of the price variable should be positive.

\section{Data}

This study is based on a unique data set that includes a complete census of all products in the most popular package size offered in thirty-three food product categories in a representative super-store in New England for each of the years 1992-99. The data are part of an ongoing survey designed to track the evolution of product offerings and label content. The data set, which records changes in nutrition content and in health and nutrition claims on food products, includes between 857 and 1,025 branded and private label 
products for each year. Each product category is a major food group including, for example, cookies, desserts, entrees, packaged meats, cereal, soups, pasta sauces, and oils. Each food category contains from three to eighty-three different brands in each of the years. Fresh commodities were excluded from the study. The data were taken directly from food labels and provide information on the amounts of specific nutrients contained in different food products as well as their prices.

To estimate the logit model we used the data for the years 1992 and 1993. In these years nutrition labeling was voluntary and determined by manufacturers. Labels were presented in the form designed and regulated by FDA requirements established in 1975. Although the NLEA was passed by the U.S. Congress in 1990, the final regulations were not published until January 1993, with the implementation deadline set for May 1994. Therefore, the data for the period 199293 can be used to test the effectiveness of nutritional quality signaling prior to the new regulation.

In order to estimate an empirical model as specified in the previous section, it was necessary to have nutrient values for all products, including those with and without nutrient content panels. The values of the nutrient content variables $\left(X_{i j}\right.$ 's) were missing for products that did not carry nutrition information panels so these values had to be constructed in order to regress the binary choice dependent variable $Y_{i}$ on the independent nutrient content variables $X_{i j}$ 's. Without this construction, it would not be possible to run regressions to test whether poor nutritional profiles affected the probability of a label being present. In 1992, approximately $30 \%$ of branded products did not have a nutrition information panel, while in 1993 this percentage decreased to $28 \%$.

To construct the missing values of nutrients, 100 product brands with nutrition information panels were randomly selected across various food categories and then the nutrient contents of the same brands were compared in 1992, 1993, and 1994. Out of 100 brands selected, about $92 \%$ had the same nutrient composition in 1992, 1993, and 1994. Based on this result, we concluded that constructing the missing values of nutrients for products that did not carry nutrition information panels in earlier years (e.g., 1992) based on our own data for the same product in later years (e.g., 1993 or 1994) was the
Table 1. Number of Brands Considered for the Logit Model

\begin{tabular}{lrr}
\hline Number of Brands & 1992 & 1993 \\
\hline Total & 987 & 982 \\
With nutrition information panels & 684 & 704 \\
With constructed nutrient content & & \\
values & 272 & 252 \\
Excluded & 31 & 26 \\
\hline
\end{tabular}

best method for completing the data set. Furthermore, as Caswell and Mojduszka (1994) pointed out, the period 1992-93 was very stagnant in product design with little change in the nutritive composition of products.

If a product had the same type of nutrient content claims in the years 1992 and 1993, the missing 1992 nutritive values were replaced with the values for 1993, if the product carried a nutrient content panel in 1993, or for 1994 if the product did not carry a nutrition information panel in 1993. This assumes that nutritional content did not change significantly over the period studied. Overall, 684 of the 987 brands in 1992 and 704 of the 982 brands in 1993 carried nutrition information panels (see table 1). Nutrition content values were constructed for 272 brands in 1992 and 252 brands in 1993. In 1992, thirty-one brands were excluded from the analysis, twenty-eight because it was difficult to construct their missing values and three because the shortening category was excluded from the analysis since its nutrient content was very uniform and there were few brands. In 1993, twenty-six brands were excluded (twenty-three due to data difficulties and three shortening brands). ${ }^{1}$

To assure the validity of the results, it would be desirable to test whether the original and filled data sets could be pooled. However, it was impossible to perform this test because the dependent variable $Y_{i}$ was always equal to zero for products without labels and always equal to one for products with labels. Therefore, for purposes of the logit model, we assumed that original and replaced sets could be pooled.

\footnotetext{
${ }^{1}$ Another data set published by the U.S. Department of Agriculture (USDA) was also considered to construct nutrient content values for products without nutrition information panels (Agriculture Handbook No. 8). However, the USDA data source did not have complete information on the nutritional composition of specific brands of foods and was very difficult to match with our data, which would have introduced inaccuracies.
} 
The complete data set containing thirtytwo food product categories was grouped into twenty food groups, based on nutrition profile and the results of tests for pooling presented in the next section. The number of nutrient content variables included in the logit model for each group varies according to the importance of specific nutrients for the entire group, collinearity among nutrient content variables, and data availability. Many of the characteristics listed on the nutrition information panel are highly correlated and the inclusion of a large number of characteristics would provide unreliable estimates due to multicollinearity. Therefore, it was necessary to select a reduced group of least linearly dependent nutritional characteristics to use. The variable selection criterion was based on the multicollinearity diagnostics suggested by Belsley, Kuh, and Welsch (see also Johnson, Reimer, and Rothrock, and Belsley). The variables chosen represent nutritional attributes of foods that are important in U.S. diets, as indicated by inclusion on the NLEA nutrition panel, and that are least collinear (Mojduszka).

Calorie, fat, and sodium content variables were included in the model for almost all of the food groups examined. The saturated fat, fiber, and sugar variables were used only for a few food groups because information on these nutrients was not required and very often not reported on nutrient content panels in 1992 and 1993. The cholesterol content variable was included in the estimations for only five groups because it was highly correlated with the fat content variable or its values were close to zero and did not vary.

The NLEA requires that the amounts of nutrients listed in the "Nutrition Facts" panel be based on standardized serving sizes to help consumers understand and compare the nutritional values of different foods. This was not the case prior to 1994 so the levels of nutrient content variables of each product in our data set were standardized based on serving sizes corresponding to the reference amounts consumed on average by an adult person, as specified and defined in the new nutrition labeling regulations. As Caswell reported, manipulation (shrinking) of serving sizes was a significant issue in product categories with higher calorie, fat, and sodium before the new regulation went into effect.

\section{Model Estimation and Results}

The data set included thirty-two food product categories. To test whether data could be pooled across categories and years, we applied a procedure used by Ben-Akiva. The test statistic did not reject the null hypothesis that some food product categories could be pooled into food groups. Those categories that could not be pooled with any other category were treated as single (individual) groups in the estimation of the logit model resulting in twenty groups overall being included in the analysis. ${ }^{2}$ In addition, the test statistic failed to reject the null hypothesis of equal coefficients in 1992 and 1993 for all thirty-two categories.

Estimates were obtained for a total of sixteen of the twenty food groups. Table 2 reports estimates of the explanatory variables hypothesized to affect the probability of the presence of a nutrition information panel on food products. The table also includes the number of all observations in each food group, likelihood ratio test statistics, Maddala $R^{2}$ 's, and percentage of right predictions. Because $Y_{i}$, the dependent variable, was equal to 1 for all of the observations in three groups (yogurt, margarine and spreads, and cereal) it was impossible to obtain estimates for these groups. In addition, for the salted snacks group 182 brands were labeled and only seven brands did not have nutrition information panels; therefore the regression results would be unreliable due to the lack of variation in the dependent variable. The logit model was estimated for fourteen food groups by a maximum likelihood procedure. The logistic and probit models were rejected for oils and soft drinks based on criteria for assessing model fit and predictive power, including the Akaike information and the Schwartz criteria (see also Maddala; Pregibon; Landwehr, Pregibon, and Shoemaker). The linear probability model was applied to these groups, with regressions run using the ordinary least squares method.

\footnotetext{
${ }^{2}$ The twenty food groups are cookies, desserts (ice cream/frozen yogurt and novelties), baked goods (frozen and fresh sweet baked goods), salted snacks (crackers, corn chips, potato chips, and other salted snacks), entrees (single serving frozen entrees/frozen dinners, family pack frozen entrees, shelf stable entrees, and frozen pizza), meats (processed meats except bacon), bacon, cheese (hard and processed), yogurt, cereal, soup, pasta sauces, vegetables (canned tomatoes, other canned vegetables, and frozen vegetables), juices (frozen, bottled, and refrigerated), soft drinks, condiments, salad dressings, margarines and spreads, butter and peanut butter, and oils.
} 


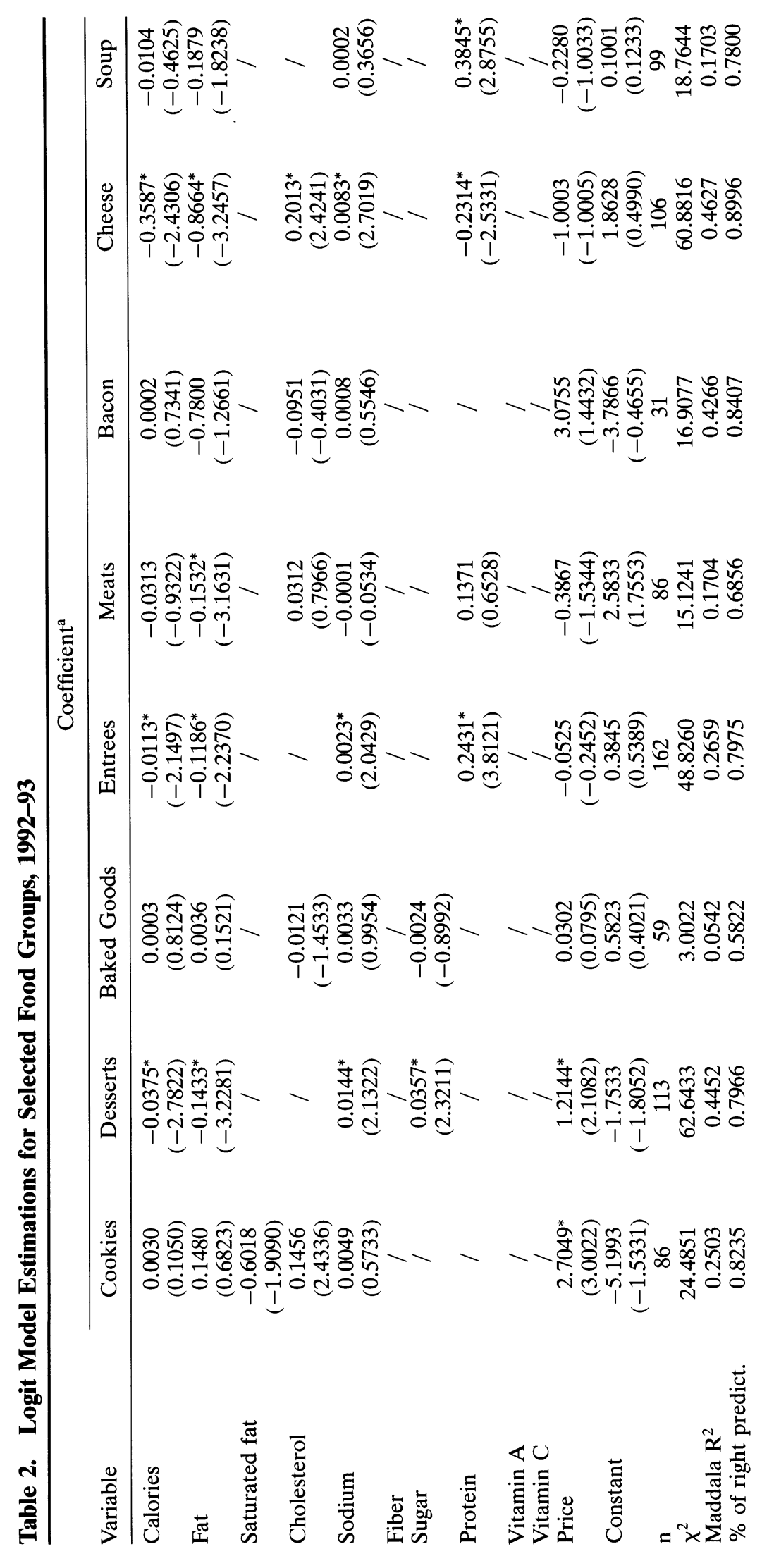




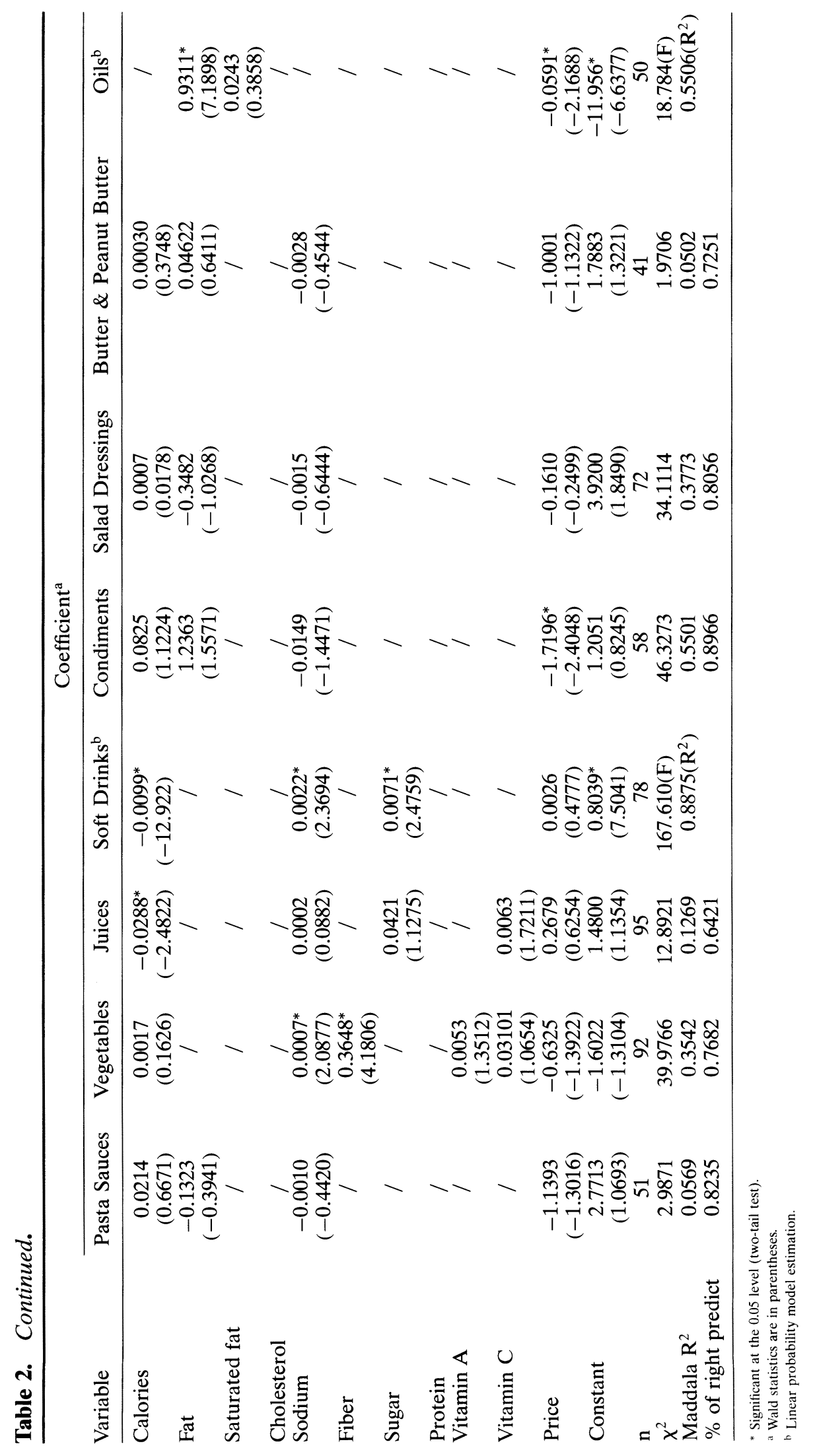


First, likelihood ratio tests were conducted to test the significance of the effect of the nutritional quality of foods and their prices on voluntary nutrition labeling. For all the food groups except baked goods, pasta sauces, and butter and peanut butter, the likelihood ratio test statistics rejected the null hypothesis that the explanatory variables other than the intercept had no impact on the manufacturer's choice probability. The logit model correctly predicted between 58 and $90 \%$ of the observations for all of the food groups. The values of the Maddala $R^{2}$ statistic, a measure of model performance, ranged from a low of 0.05 for the butter and peanut butter group to a high of 0.55 for the condiments group. These results provide evidence that the nutritional quality and price of food had a significant impact on the voluntary disclosure of information in thirteen of twenty food groups considered in this study.

Our analysis of the estimates of the logistic model begins with horizontal (nutrient by nutrient) analysis. The calorie variable was considered in all of the food groups except oils. The significant (at the 5\% level) and negative coefficients on the calorie variable in the desserts, entrees, cheese, juices, and soft drinks groups showed that manufacturers of products containing more calories were less likely to disclose their nutrient content levels. This result is consistent with a totally effective quality signaling model. In the remaining ten food groups the calorie content variable was insignificant suggesting that the calorie level in these foods did not affect the probability of a nutrition information panel being present on food packages. This result is inconsistent with the totally effective quality signaling thesis.

Fat, an important macronutrient variable, was included in the model for thirteen food groups. The estimated coefficients on fat among the food groups of desserts, entrees, meats, and cheese were statistically significant and negative. This suggests that food products in these groups with lower fat content were more likely to carry a nutrition information panel than other products. Within these high fat foods, the fat level had a significant and negative effect on the probability of nutrition labels being present on food product packages. On the other hand, for the oils group, the estimated coefficient on the fat variable was highly significant and positive, which means that in this group a higher level of fat content did not decrease the probability of nutrition labeling. This result suggests that disclosure of information on the nutrient content of oils did not conform to Grossman's thesis. It is noteworthy that the oils group consists of high fat content products. Therefore, it would be more appropriate to test how the content of saturated, polyunsaturated, or other fatty acids affected the probability of voluntary information disclosure in this group. Information on saturated fat was available for most of the brands and the saturated fat content variable was included in the estimation of the linear probability model for the oils group. However, its effect on the probability of nutrition labeling was statistically insignificant. This might be due to higher collinearity between the fat and saturated fat variables. The coefficients on fat among the eight remaining food groups were insignificant and thus did not support Grossman's thesis.

The saturated fat variable was included in one additional group (cookies) and the cholesterol variable was included in five groups (cookies, baked goods, meats, bacon, and cheese) for the logit model estimation. The effect of these nutrients on the manufacturer's choice probability was not significant in any of these cases except for cholesterol in cheese. This might result from high collinearity between fat and saturated fat, and between fat and cholesterol.

Another macronutrient variable, sodium, was included in the model for all of the food groups except oils. The estimated coefficients on sodium for food groups such as desserts, entrees, cheese, vegetables, and soft drinks were statistically significant but positive. This suggests that food products with low sodium content within these food groups were not more likely to carry a nutrition label than other products. In this case, Grossman's hypothesis was not supported by our data. The sodium content of food products in these groups did not have a negative effect on the probability that these products were labeled for their nutrient levels. However, desserts, cheese, and soft drinks, as well as vegetables, do not belong to high sodium content groups. The means of sodium content for these food groups were $60,264,37$, and $302 \mathrm{mg}$ per serving, respectively. This compares, for example, to the soup group where the mean level of sodium was $954 \mathrm{mg}$ per serving. In the soup group as well as in the remaining ten 
groups, the coefficient on sodium was statistically insignificant and did not conform to Grossman's model.

One of the most important desirable nutrients, fiber, was considered in the vegetables group only and its effect was significant and positive which means that the higher the fiber content the more likely it was that vegetable products carried nutrition labels in the years 1992-93. The fiber variable was not included in the model for any other food groups because of missing data problems. Sugar was considered in the desserts, baked goods, juices, and soft drinks groups. The estimated coefficient for the sugar content variable was positive and significant in the desserts and soft drinks groups, which means that higher sugar content did not decrease the probability of a label being present on products in these groups.

The protein variable was considered for the estimation of the logit model for entrees, meats, cheese, and soups. For the entrees, cheese, and soup groups estimated coefficients on protein were significant; however, they were positive for two groups: entrees and soups, whereas in the cheese group the effect of protein on the probability of nutrition labeling was negative. For meats the coefficient on the protein variable was positive but insignificant. Lastly, two other desirable nutrients, vitamin $\mathrm{A}$ and vitamin $\mathrm{C}$, were included for vegetables and juices. In both cases the estimated coefficients were not statistically significant.

Price is included as an economic variable in the estimation of the logit model for all of the food groups as a proxy for manufacturers' production costs. The estimated coefficient of the price variable was positive and significant in two groups, cookies and desserts. Within these two groups products with higher prices were more likely to have nutrition information panels. In two additional groups, condiments and oils, the estimated coefficient of price was significant but negative, which indicated that higher priced products within these groups were less likely to carry a nutrition label. For the remaining twelve food groups the price variable was not significant. The above results suggest that, overall, there was no significant relationship between prices (manufacturers' cost) and voluntary disclosure of information on the nutritional quality of food. Higher prices did not trans- late into a higher probability of information disclosure. ${ }^{3}$

Yatchew and Griliches have examined the issue of potential problems associated with omission of a significant variable in the setting of probit and logit models. They found that even if the omitted variable is uncorrelated with the included one, the coefficient on the included variable will be inconsistent. Any of the three standard methods of hypothesis testing (i.e., the Wald, likelihood ratio, or Lagrange multiplier tests) can be used to analyze the specification problem associated with omitting price from the estimations. The likelihood ratio test shows what happened when the price variable was excluded from the model for the cookies, desserts, condiments, and oils groups. In all of these foods, the price variable was significant. The null hypothesis tested was that $\beta_{\text {price }}=0$ for each of the above four groups. The likelihood ratio (LR) statistics were computed as:

(2) $\mathrm{LR}=-2\left[\ln L_{r}-\ln L\right]$

where $\ln L_{r}$ and $\ln L$ are the log-likelihood functions evaluated at the restricted and unrestricted estimates, respectively. For all four categories, the hypothesis that the coefficient on the price variable was zero was rejected. Thus, if the price variable was not considered for the estimation of the logit model the estimated coefficients of the other included variables would be inconsistent. ${ }^{4}$

To be able to draw conclusions about the overall effectiveness of private quality signaling, it is also useful to analyze the impact of nutritional quality on labeling by food groups (vertical analysis). As noted earlier, within the four food groups of salted snacks, cereal, yogurt, and margarine and spreads, almost all products were labeled so there was no

\footnotetext{
${ }^{3}$ Inclusion of the price variable as an independent (exogenous) variable creates a question whether the estimates obtained from a single equation method suffer from simultaneous equation bias, which would be the case if the price variable was determined endogenously. A Hausman test was used for independence of the regressors and stochastic error term, to examine whether the estimated coefficients are unbiased (Smith, Even). This test, using annual total expenditures on advertising (in million of dollars) on each brand for the cookies, soft drinks, and soup categories as an extra exogenous variable, indicated that there is no simultaneity bias and that the maximum likelihood estimates for cookies, soft drinks, and soups are consistent. We were unable to test the other product categories due to data availability.

${ }^{4}$ When the price variable was excluded from the model, the magnitudes of the estimated coefficients changed. In addition, the coefficient on the sodium variable in the condiments group changed sign from negative to positive but remained insignificant. The significance of the estimated coefficients did not change in any of the four food groups.
} 
relationship between voluntary disclosure of information and the amounts of nutrients in these foods. Grossman's thesis was not supported for products within these groups. In addition, the whole regressions were insignificant for baked goods, pasta sauces, and butter and peanut butter and also did not support Grossman's model.

In a further four food groups, cookies, bacon, condiments, and salad dressings, the hypothesized quality signaling process for nutrient content can also be rejected. No nutrient content variables were statistically significant in these groups. For cookies the estimated coefficient on price was statistically significant and positive which suggests that in this food group price (manufacturers' costs) had a significant and positive effect on the probability of nutrition information panels being present on packages. When the price of cookies was higher the probability of labeling for their nutritional quality was also higher. For condiments the price variable was statistically significant but negative. Price was not significant in explaining labeling probability for either bacon or salad dressings. On the other hand, in the oils group the fat content had a significant but positive effect on the probability of information disclosure and the price variable was statistically significant but negative. Overall, the hypothesized pattern of quality signaling was not supported by our data in these five food groups.

For eight other food groups, desserts, entrees, meats, cheese, soup, vegetables, juices, and soft drinks, the results are inconclusive because, for example, one undesirable nutrient had a negative effect and another undesirable nutrient had a positive or no effect on the probability of information disclosure. Also within the soup group the fat and sodium content variables were not statistically significant; however, the protein variable was statistically significant and positive. To be able to provide more conclusive results for these groups it would be necessary to rank nutrients according to their importance within a group. For example, if we rank fat as more important than sodium the quality signaling thesis would be supported in the desserts, entrees, meats, and cheese food groups. If we rank fiber higher than sodium then the results would be consistent with Grossman's model for vegetables. If we consider protein as more important than fat and sodium then Grossman's thesis would be supported for the soup group. If we evaluate calories as more important than sodium then Grossman's model would be supported in five additional food groups: desserts, entrees, cheese, juices, and soft drinks.

Overall, the results of the test of Grossman's model show that private quality signaling was not reliably at work in food markets prior to implementation of mandatory nutrition labeling. There was no clear, consistent pattern in what types of products within food groups carried nutrition information panels and consumers could not reliably assume that a product without a nutrition information panel had a poorer nutrition profile.

\section{Conclusions}

This study investigated the effectiveness of markets in providing information to consumers on the nutritional quality of processed foods. Grossman's model of totally effective quality signaling was used to test whether markets were effective in information provision prior to implementation of the Nutrition Labeling and Education Act of 1990. Our data set allowed quantification of the nutritional quality of food products by measuring their nutritional characteristics. It also allowed estimation of the effect of these nutritional characteristics on the probability of voluntary information disclosure.

According to Grossman's model, voluntary information provision on the nutritional quality of processed foods would have been effective if higher quality products had nutrition information panels on their packages and those with lower quality did not. In this case consumers would be able to distinguish the nutritional quality of food products at the point of purchase. With effective private quality signaling, government regulation of nutrition labeling would be unnecessary.

Our test of a model of totally effective nutritional quality signaling provided mixed results from one food group to another. For example, within the four food groups of salted snacks, cereal, yogurt, and margarine and spreads there was no relationship between voluntary nutritional labeling and the nutritional profile of food products because almost all products were labeled regardless of their nutritional profiles. While not directly supporting the Grossman model, these food groups could be viewed as having relatively effective quality signaling in 
that most products were labeled and crosscategory comparisons (e.g., margarine and spreads versus butter) could be facilitated. In the three additional groups of baked goods, pasta sauces, and butter and peanut butter, the whole regressions were insignificant thus not supporting Grossman's model. In the four other food groups of cookies, bacon, condiments, and salad dressings there were no significant nutritional characteristics variables. For oils a significant but positive coefficient on fat did not support Grossman's thesis. Within the eight other food groups of desserts, entrees, meats, cheese, soup, vegetables, juices, and soft drinks, the estimated regressions did not provide conclusive results.

In summary, the theoretical assumptions of a totally effective quality signaling model were not broadly supported in the real world market for nutritional quality. Incentives for voluntary disclosure of nutritional content by food processing companies did not generally result in reliable and consistent quality signals to consumers. In this setting, requirements for mandatory nutrition labeling were likely to increase significantly the amount of information available to consumers.

[Received May 1998; accepted July 1999.]

\section{References}

Akerlof, G.A. "The Market for 'Lemons': Quality Uncertainty and the Market Mechanism." Quart. J. Econ. 84(August 1970):488-500.

Belsley, D. Conditioning Diagnostics, Collinearity, and Weak Data in Regression. New York: Wiley, 1991.

Belsley, D., E. Kuh, and R. Welsch. Regression Diagnostics: Identifying Influential Data and Sources of Collinearity. New York: Wiley, 1980.

Ben-Akiva, M.E. Discrete Choice Analysis. Cambridge MA: The MIT Press, 1985.

Caswell, J.A. "Current Information Levels on Food Labels." Amer. J. Agr. Econ. 74(December 1992):1196-1201.

Caswell, J.A., and E.M. Mojduszka. "Using Informational Labeling to Influence the Market for Quality in Food Products." Amer. J. Agr. Econ. 78(December 1996):1248-53.

. "Manufacturers' Responses to New Food Labeling Regulations." Selected poster paper presented at the NE-165 and WRCC-72 Interactions Between Public Policies and Private Strategies in the Food Industries, Research Conference, Montreal, Quebec, June 1994.

Darby, M.R., and E. Karni. "Free Competition and the Optimal Amount of Fraud." J. Law and Econ. 16(April 1973):67-88.

Even, W.E. "Testing Exogeneity in a Probit Model." Econ. Letters 26, no. 2(1988): $125-28$.

Frazao, E., and J.E. Allshouse. "Nutritionally Improved Foods in Grocery Stores: 198993." The Economics of Reducing Health Risk From Food. J.A. Caswell, ed., pp. 149-161. Storrs CT: Food Marketing Policy Center, 1996.

Grossman, S.J. "The Informational Role of Warranties and Private Disclosure about Product Quality." J. Law and Econ. 24(December 1981):461-89.

Hooker, N.H., and J.A. Caswell. "Regulatory Targets and Regimes for Food Safety: A Comparison of North American and European Approaches." Economics of Reducing Health Risk from Food. J.A. Caswell, ed., pp. 317. Storrs CT: Food Marketing Policy Center, 1995.

Ingersoll, B. "Labels on Meats Fail to Provide Nutrition Data." Wall St. J. 5 March 1991, p. B1.

Ippolito, P.M., and A.D. Mathios. "Information, Advertising, and Health Choices." Rand J. Econ. 21(Autumn 1990):459-80.

. "New Food Labeling Regulations and the Flow of Nutrition Information to Consumers." Paper presented at the Marketing and Public Policy Conference, East Lansing, MI, 4-6 June 1993.

Johnson, S.R., S.C. Reimer, and T.P. Rothrock. "Principal Components and the Problem of Multicollinearity." Metroeconomica 25(September-December 1973):306-17.

Lancaster, K. Consumer Demand: A New Approach. New York: Columbia University Press, 1971.

Landwehr, J.M., D. Pregibon, and A.C. Shoemaker. "Graphical Methods for Assessing Logistic Regression Models.” J. Amer. Statist. Assoc. 79(March 1984):81-83.

Maddala, G.S. Limited-Dependent and Qualitative Variables in Econometrics. Cambridge UK: Cambridge University Press, 1983.

Mojduszka, E.M. "Manufacturers' Responses to New Nutrition Labeling Regulations." PhD dissertation, University of Massachusetts, Amherst, 1997. 
Nelson, P. "Advertising as Information." J. Polit. Econ. 82(July/August 1974):729-54.

-. "Information and Consumer Behavior.” J. Polit. Econ. 78(March/April 1970): 311-29.

Pregibon, D. "Logistic Regression-Diagnostics." Ann. Statist. 9, no. 4(1981):705-24.
Smith, R.J. "Testing for Exogeneity in Limited Dependent Variable Models Using a Simplified Likelihood Ratio Statistic." J. Appl. Econometrics 2(July 1987):237-45.

Yatchew, A., and Z. Griliches. "Specification Error in Probit Models." Rev. Econ. and Statist. 67(February 1984):134-39. 